\title{
Response Tokens and Their Sequential Action in the Teacher Third Turn (Note 1) A Conversation Analysis Case Study in the EFL Classroom
}

\author{
Asma Ebshiana \\ Department of Modern Languages and Linguistics, University of Huddersfield HD \\ 3DH, Queensgate, Huddersfield, United Kingdom \\ E-mail: a_bushina1977@yahoo.com
}

Received: December 16, 2019

Accepted: January 29, 2020

Published: March 1, 2020

doi:10.5296/ijl.v12i2.16585

URL: https://doi.org/10.5296/ijl.v12i2.16585

\begin{abstract}
In classroom settings, students` responses are regularly evaluated through the ubiquitous three-part sequence. It is through this pattern that teachers encourage student participation. Usually, the teacher uses response tokens such as "Okay", Right" /" Alright", "Mhm" "Oh", in the third turn slot. These tokens are crucial and recurrent because they show where the teacher assesses the correctness or appropriateness of the students' responses either end the sequence or begin a turn which ends the sequence. Moreover, such tokens have an impact on the sequence expansion and on the students' participation. This article is a part of a large study examining the overall structure of the three-part sequence in data collected in an English pre-sessional programme (PSP) at the University of Huddersfield. The present article focuses on the analysis of naturally occurring data by using Conversation Analysis framework, henceforth (CA). A deep analysis is performed to examine how response tokens as evaluative responses are constructed sequentially in the third turn sequence as a closing action, whilst considering how some responses do not act as a closing sequence, since they elaborate and invite further talk. The results of response tokens have shown that they are greatly multifaceted. The analysis concluded that not all responses do the same function in the teacher's third turn. Apart from confirming and acknowledging the student responses and maintaining listenership, some invite further contribution, others close and shift to another topic that designates closing the sequence, and some show a "change of state". Their functions relate to their transitions, pauses and their intonation in the on-going sequence.
\end{abstract}

Keywords: Response tokens, Conversation analysis, Three-part sequence 


\section{Introduction and Literature Review}

This article examines and focuses on response tokens in the teacher's third turn. The third part of the sequence is central to classroom talk - many institutional environments are characterized by adjacency pairs, but classroom talk is distinguished by having the third turn. Accordingly, taking a deep look at teachers performing in the third turns, which may assist us in better understanding what teachers are achieving in this classroom (PSP). Response tokens are a type of post-expansion by the teacher, who either accepts, rejects and/or evaluates the student's response, which either acts as a "sequence-closing third" (Schegloff, 2007), or expands the sequence if the teacher initiates a repair. Examples of such responses include expressions such as "Okay" and "Oh" and assessments such as "Alright" and "That's fine" and on some occasions, there could be a combination of these minimal expansions in the same turn - for example "Alright okay" or responses such as "Oh okay great" as an assessment. (Ebshiana, 2019).

Different response tokens have certain differences in use, nonetheless, they share some similarities. Such tokens can stand on their own in a speaker's turn, however, some for instance, "Oh" do so relatively uncommonly, and as such can initiate some of the briefest turns in talk (Gardner, 2007). This article explores the positioning and design of the responses in the teacher's slots; showing their impact on the student responses and on the sequence expansion.

These tokens often 'unclassified', 'homogenous', 'messy' linguistic items may say more than we assume, adding more meaning to the sequence (Huq \& Amir, 2015). These tokens patterns, positions as well as characteristic traces can help shed light on the interactional details, reshaping teacher roles and learner contribution (Walsh, 2011a). Despite these tokens being minimal and often so brief, they still help develop our understanding of classroom settings in terms of their interactional dynamics therein. An expanded understanding of such tokens brings an awareness of the teacher's role in facilitating student responses, to ensure participation, and to create a space for articulating students' thoughts and speech.

These third turn responses are specifically important in classroom talk. It is the recurrent occurrence of these third turns that give classroom talk the characteristics that distinguishes it from other kinds of talk. What is important is that it links to the fact that the teacher (assesses the student's response, thus showing that what is going on is testing the student, not genuinely seeking information; the teacher mostly already has that information). This is particularly where we see that classroom talk is not just about someone asking questions and someone answering them, it is about the teacher testing the students' knowledge through questions and then commenting on those answers using variable responses.

These evaluative responses have a vital role in shaping the sequence in relating to closing the sequence or in minimally expanding the sequence for more elaboration. Also, these responses have a significant impact on the on-going sequence, for instance some work as closing implicative while, others invite collaboration. Moreover, such an evaluative response can stand alone in the third turn, whereas, some can be joined with other responses making it more complex in the third turn for example, taken from the current data on the one hand the 
teacher might produce an explicit evaluative response; on the other hand, the teacher might refer back to the prior turn on the student's response as a repair initiation " $>$ okay but $<$ what is your argument" (Ebshiana 2019). In addition, prosodic features such as falling and rising intonation have an important role in designing the sequence as well as in relation to closing down the sequence or for more expansion and hence, encourage student's participation.

Moreover, these responses can provide a source of knowledge in terms of their action for the participants. Although they are small connections, they have the potential to develop the trajectory of talk between the participants (Gardner, 2007). For example, "Okay" is used transitionally, as a free-standing receipt indicator working for both recipients and the current speakers. "Okay" has been established in the work of Sacks and Schegloff (1973) who studied pre-closings to phones calls. According to the authors, "Okay" can act as a pre-closing if it performs as an adjacency pair, emerged with an acknowledgement token such as "Right", "Alright". In this case, "Okay" works as a topic closure, marking how the speaker intended to move to another area of business and that there is nothing new to add to the current topic (Shegloff \& Sacks1973). The "Oh" token can occur as free standing or with other units (Schegloff, 2007) as well as a "change of state" token, as identified by Heritage (1984a) meaning that the recipient or the hearer has received new information about the situation, thus transitioning the hearer from not knowing $\left(\mathrm{K}^{-}\right)$to a position of knowing $(\mathrm{K}+)$ (Heritage \& Clayman, 2010). However, in some instances, this "change of state" can be manifested as a response to an assessment treating the prior information as a complete and closing implicative (Heritage, 1984; Jefferson, 1993). In my data, the token "Oh" occurs in combination with other tokens, such as "Okay" and positive assessment + Wh question inviting for further talk (Ebshiana, 2019). Moreover, "Oh" in this data never found as a free standing always followed by other response tokens. In this respect such occurrences have different functions and impact on the sequence (Ebshiana, 2019). The "Right" token is used to achieve a recognition of the element of talk which it refers to, or a conception from that unit or element of talk has been acknowledged to be connected to another unit from the previous talking (Gardner, 2007). However, the other use of "Right" as a 'change-of-activity' token, recommends shifting out of the present task or action into another, and is placed recurrently at the end of extended sequences, acting as a pre-closing token in the closings of conversation (Gardner, 2007). This it will be discussed in an analysis of the current data.

Another practise of "Right" is also as a reduced type of another token - for instance 'Alright'. In some occasions it is obvious from the analysis that similarly "Right"/ "Alright" functions in the same way as the acknowledgement token "Okay", when it comes to shifting the talk to another new business, or "changing the activity" Although "Okay" indicates a progression or confirmation check, "Right" works on the information state structure, where its usage among sharing knowledge is either from the outside world or relates to the subject content that the student and the teacher are familiar with in the classroom (Gardner, 2005, 2007). Here, in this article I examine the response token "Right" in two patterns, first "Right" as shifting to another topic"; second, as "inviting for more talk". What is interesting here is that "Right" has more than one function, and can work as a sequence closing, where there is nothing to add and the teacher needs to move on to another task. Also, it can work as an invitation to 
further collaboration from the student, when it occurs at turn initial in the third turn aligned with high intonation. (Ebshaina, 2019). Another type of response that is also found in the teachers" third turn are the "continuers" "Mm" and "hm" or sometimes uttered as one "Mm $\mathrm{hm}$ ". The main function of theses "continuers" is to give a signal to the main speaker, letting them continue talking or speaking, and showing, that they are listening to the recipient (Schegloff, 1982). In fact, these tokens "Mm" and "hm" assist the current speaker to understand the listeners" "orientation" or "affiliation" (Wong, 2000). The present article aims to analyse these tokens showing their multifaceted function on the student responses and the expansion of the sequence.

\section{Data and Method}

The participants in the study were 24 adult EFL learners undertaking an academic English course who were recorded and observed over a six-month period. From 20 hours of recordings of interactions that took place during their pre-sessional English language course at the University of Huddersfield, 4 hours were selected and transcribed. The current study uses CA to investigate patterns, sequence structures in terms of the turn-taking, sequence organisation and repair initiation in the three-part sequence, which is collaboratively accomplished in this classroom.

Research on classroom discourse has been extensively studied for a long period of time and different approaches have been adopted from a wide range of disciplinary perspectives including, "Discourse Analysis" (Sinclair \& Coulthard, 1975) and "Critical Discourse Analysis", for instance (Rymes, 2015). Despite the fact that such approaches have made a substantial contribution to our knowledge of the language classroom (either in the first language or in the second language classroom), such approaches have been criticised as focusing largely on coding and quantifications, missing the actual moment by moment development of the interaction (Sert, 2015). Therefore, some researchers have seen the need to shift to consideration of the details of the interaction through a new perspective on L2 classrooms, employing Conversation Analysis (CA), as a micro analysis approach.

CA is mainly interested in talk as actions and how the production of utterances "is seen not in terms of the structure of language, but first and foremost as a practical social accomplishment" (Hutchby \& Wooffitt, 2008, p. 12). Moreover, the structure of language; talk is not observed as chains of separate acts, however, as a cooperatively and sequentially organised phenomenon (ten Have, 2007).

CA has been defined in a number of ways as stated by (Psathas, 1995, p. 2), CA studies "the order/organisation/orderliness of social action, particularly those social actions that are located in everyday interaction, in discursive practices, in the sayings/telling/doings of members of society". Fundamentally, the main point in CA is that "social actions are meaningful to those who produce them and that they have a natural organisation that can be discovered and analysed by close examination" (Psathas, 1995, p. 2). Hence, the objective is to discover and describe the structure of the mechanisms / or rules that produce and constitute the organisation.

It is worth noting here that CA functions as a detailed analysis of interactional events, recordings, and in-depth transcriptions, instead of coding, counting, or other brief 
descriptions. It describes in detail how sequences are organised in terms of utterances and actions, as well as how participants open and close their conversation. CA has its own principles and features. Hutchby and Wooffitt (1998, p. 23) list the following as four fundamental principles of CA:

- Talk-in-interaction is systematically organised and deeply ordered

- The production of talk-in-interaction is methodic

- CA should be based on naturally occurring data

- One should not assume that a piece of data is not worth analysing before attempting to analyse it.

The aforementioned principles are essential to my study in examining the sequence organisation, as I have considered the data for orderly patterns in determining how the teachers initiate the sequence. CA gives In-depth examinations of interactions using detailed transcription. Analysis was conducted through the repeated listening to and watching of the original data and examination of transcripts in an 'unmotivated way' (Sacks 1984, 2007) so as to avoid projection of a priori assumptions onto the data. That is to say, the data were examined with no preconceived research questions in mind. As a result of the observations, my attention was drawn to the teachers' unique deployment of the response tokens in the teachers' third turns. After making a collection of the phenomenon, a line-by-line analysis was conducted in each case.

In CA, only naturally occurring interactions are acceptable as data; every minute through a linguistic detailing for example of speakers' pauses, sound, stress pitch, and also non-linguistic elements, such as strengthening the word or in-breaths, and overlaps is considered relevant in uncovering participants' orientation towards the interaction. I include pauses, I timed them to the nearest tenth of a second, overlaps, prosody and falling and rising tone in order to get a fine-grained analysis through teacher and student interaction. Intonation is interactional resource used by the teacher in initiation questions, providing evaluation and initiating repair in the sequence. However, I only will use them as an additional data the analysis is not measuring them acoustically. In order to enhance confidentiality, I refer to the teacher by T, and students as S1, S2, and S3 and when a group of students are participating this is referred to as SS. However, their identities such as nationalities or genders are not revealed. The extract is referred to as [AE: TST: May 2015] (Note 2). All of the interactions in the data extracts were performed in English. I transcribed the various interactions in the chosen (PSP) classroom from the audio recorder (Zoom MH2N) and ended up with a comprehensive written record of the talk.

\section{Findings and Discussion}

The analysis demonstrates different patterns of how these tokens "Okay", "Right" / "alright", "mhm" and "Oh" occur sequentially among different activities, as well as assess the impact of these responses on the teachers' third turn and the sequence they build on.

\subsection{The Response Token "Okay" in the Teacher's Third Turn}

In the following extract "Okay" as a response token marking closing and assessment where 


\section{NI Macrothink}

there is nothing to add.

Extract-1 [AE: TST: August 2015]

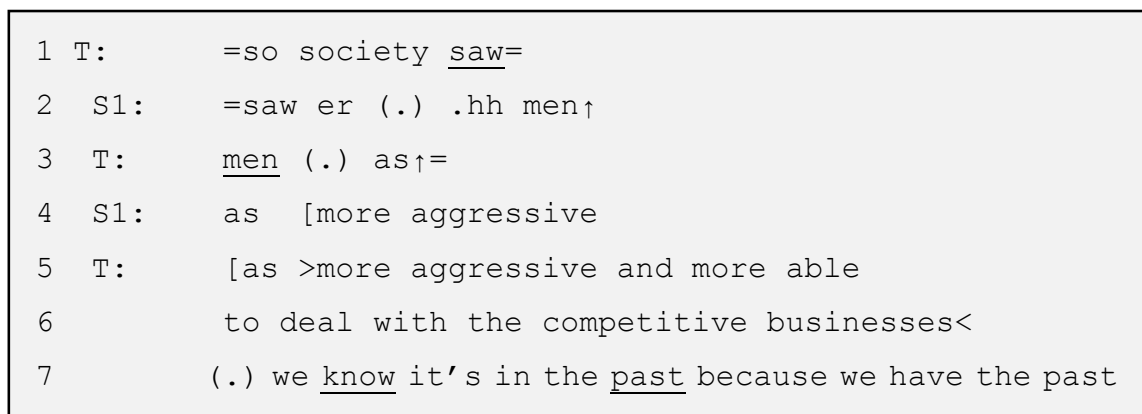

The teacher produces in the third turn "Okay" as a closing implicative affiliated with a positive assessment " $\uparrow$ Okay excellent". Here, the teacher assesses the student response using an upgrade agreement, marking no further talk, so one can say that "Okay" performs as a free-standing token marked as closing the sequence with no adding talk.

Extract 2 [AE:TST: July 2015]

In the next example, "Okay" has a different pattern: it is combined with other affirmative responses, function as non-closing and inviting further expansion.

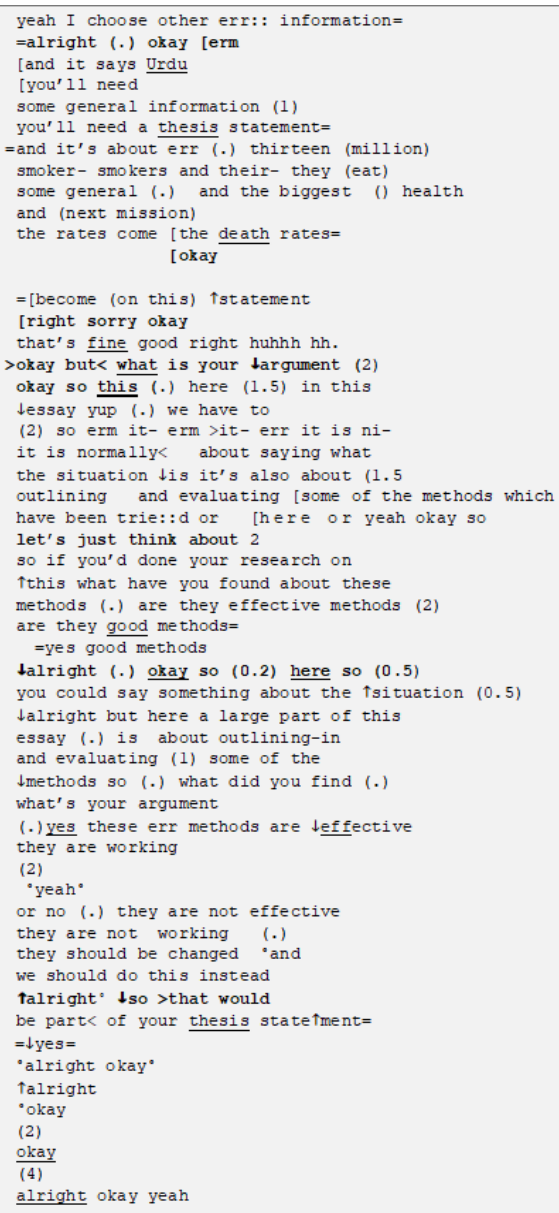




\section{I Macrothink}

International Journal of Linguistics

ISSN 1948-5425

2020, Vol. 12, No. 2

The teacher initiates "Okay" affirming the student's response, however, this "Okay" combined with "but" as disagreeing with the student responses as in line 17 ">okay but $<$ what is your argument" and immediately the teacher initiates repair in terms of a Wh-question, followed by a (0.2) second pause. This combination does not function as closing the sequence, it invites further talk and more explanation. The teacher holds the turn when there is no response from the student to the teacher's questions. After that, the teacher produces the acknowledgement token "Okay" as free standing and provides feedback to the student about what should be done in his essay writing.

\section{2 "Right" as Shifting to Another Topic}

Extract 3[AE:TST: July2015]

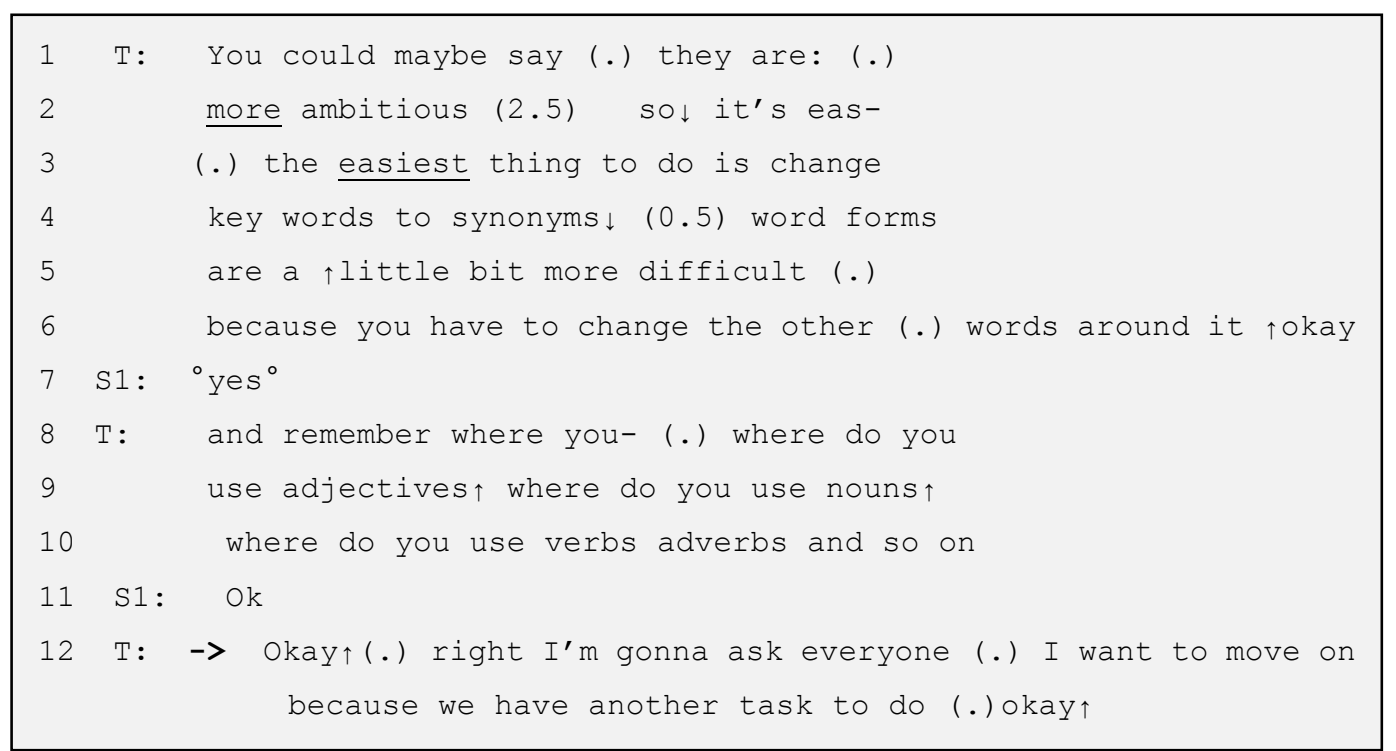

The teacher initiates "right" in the medial turn after a micro pause, line 12 "right I'm gonna ask everyone (.) I want to move on because we have another task to do (.) okay $\uparrow "$. This "right" marks or functions as a topic shift, moving on to other business (Gardner, 2001). Here, the teacher asks for permission to introduce a new topic, and requests no further proceeding talk. Interestingly, another "okay $\uparrow$ " is produced at the TRP, with a rising tone encounter, ensuring a tag question.

Without a doubt this "right" token marks a proposed change of activity, the teacher does end the sequence by explaining further that $s /$ he needs to move on to other business aligned with "okay". This finding supports the views of Gardner (2007) and Lee (2017). 


\section{$\Lambda$ Macrothink}

\section{3 "Right” as Acknowledging Confirmation Indicating Non-Closing}

Extract 4 [AE:TST: August 2015]

\begin{tabular}{|c|c|c|}
\hline 1 & S2: & increasing ${ }^{\circ}$ population ${ }^{\circ}$ \\
\hline 2 & $\mathrm{~T}:$ & \okay (.5) yeah so how can this $\uparrow$ help some- err \\
\hline 3 & & a- a countries \\
\hline 3 & & (.) but maybe not help others= \\
\hline 4 & S2: & =yahh: : ermm \\
\hline 5 & & (1) \\
\hline 6 & $\mathrm{~T}:$ & listen please and $\uparrow$ think listen \\
\hline 7 & S2: & it's err:: I think it's a disadvantage \\
\hline 8 & & if the growing population is $\downarrow$ increasing $=$ \\
\hline 8 & $\mathrm{~T}:->$ & $=\uparrow r i g h t$ \\
\hline 9 & S2: & ah: : : because of err:: (.) need $\uparrow$ more \\
\hline 10 & & a- foods (.) need m- err basic needs basic \\
\hline 11 & & human needs is more: : (1.5) and $\downarrow$ err \\
\hline 12 & & (.) that's like err (.5) food house cloths \\
\hline 13 & & $(.5)$ \\
\hline 14 & & and $\uparrow a l s o$ >education< and also the: \\
\hline 15 & & $m:: m::::$ \\
\hline 16 & & (1.5) health $=$ \\
\hline 17 & $S$ & $=$ workplace a [lot of ] >a lot of \\
\hline 18 & S2 & (point) about [work[place \\
\hline 19 & $\mathrm{~T}:$ & [ alright $\left[\downarrow_{y e a h}\right.$ \\
\hline 19 & & \\
\hline 20 & $\mathrm{~T}:$ & [ alright $\left[\downarrow_{\text {yeah }}\right.$ \\
\hline
\end{tabular}

Here, the teacher is using the verbs listen and think with rising tone and stress representing emphasis. After S2's response to the question, the teacher in line 8 produces the acknowledging confirmation "right", with high intonated tone. The "right" here indicates a recognition and confirming knowledge. What is interesting is the student orients to the teacher's "right" as an incomplete sequence, or in other words, non-closing sequence and there is more to add. Consequently, the student gives a response by exploring and giving justification by using 'because of err::' as well as providing examples in line 9. Although, there are pauses positioned between the utterances, the teacher does not self-select to participate in the turn, leaving the turn to the student for more free expression.

On some occasions, "right" appears to be a shorten form of "Alright", a token most usually used in settings in which interlocutors are shifting from one subject or action to another action particularly, when the boundary is major (Beach 1993, Gardner 2001). "Alright" is in 


\section{Macrothink}

International Journal of Linguistics

ISSN 1948-5425

2020, Vol. 12, No. 2

various practices parallel to "Okay" as a response token, although the former is found more with activity shifts, and with high speakership incipiency, usually with dropping tone (Gardner 2001).

The two following extracts, are examples of a typical "alright" in the EFL classroom. Although they occur in different positions in the sequence, they all are marked at a shift level.

\section{4 "Alright" Changing Topic or Activity}

Extract 5 [AE:TST: April 2015]

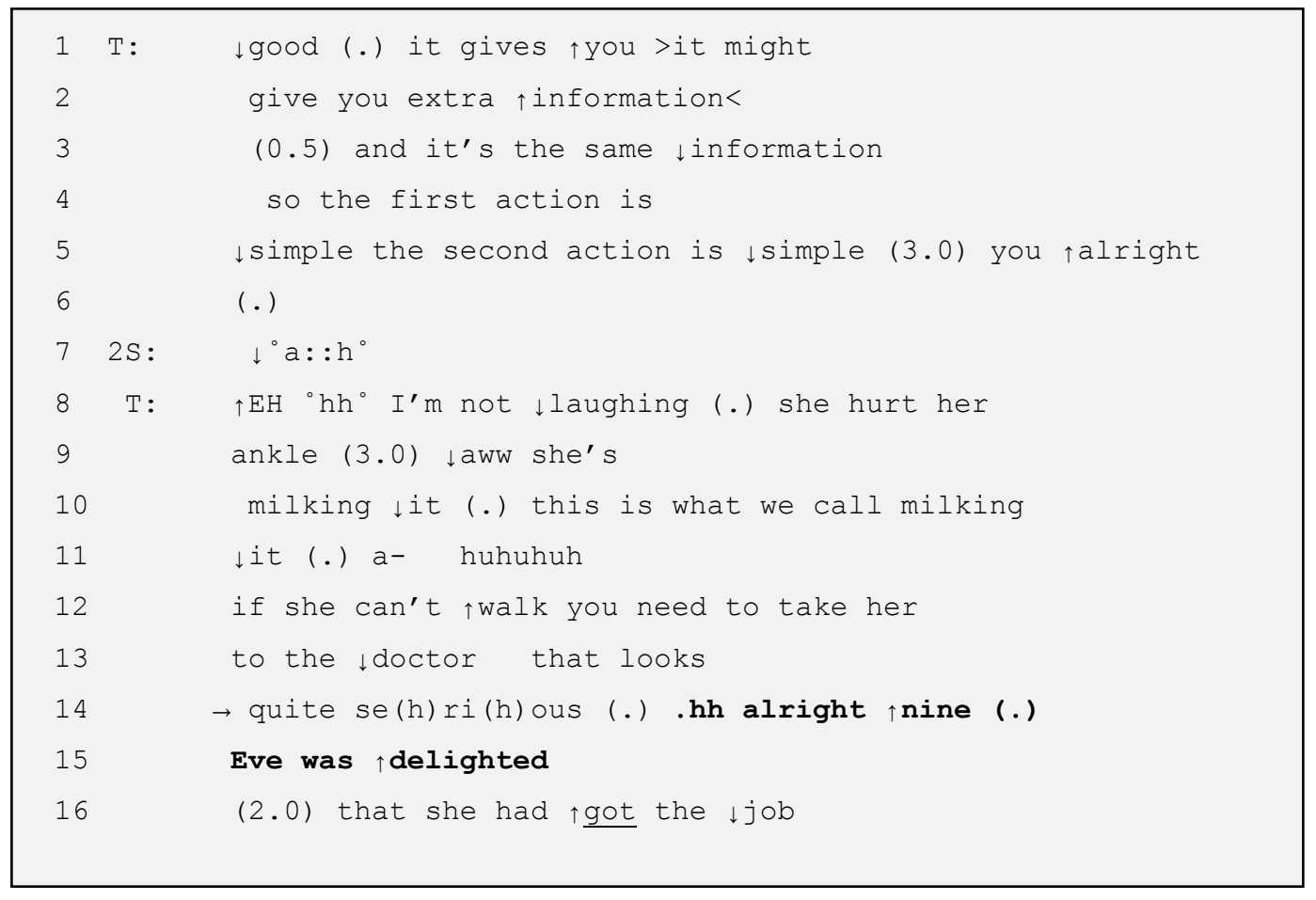

It is clear in the extract above that the teacher's "alright" in line 14 occurs nearly at the TRP transition, indicating a level of shifts followed by $h h$ inbreath, which is delivered before "alright". This can be considered influencing further talk and indicating changing activity. The "alright" functions as moving to another point, where the teacher produces number " $\uparrow$ nine (.)”, with high intonation, showing an emphasis that here is no need to go back to the previous utterances. However, the following example of "alright" also marks a changing activity, but it is placed at the beginning of the turn as initials, unlike in the previous example. 


\section{1) Macrothink}

3.5 "Alright + So"

Extract 6 [AE:TST: August 2015]

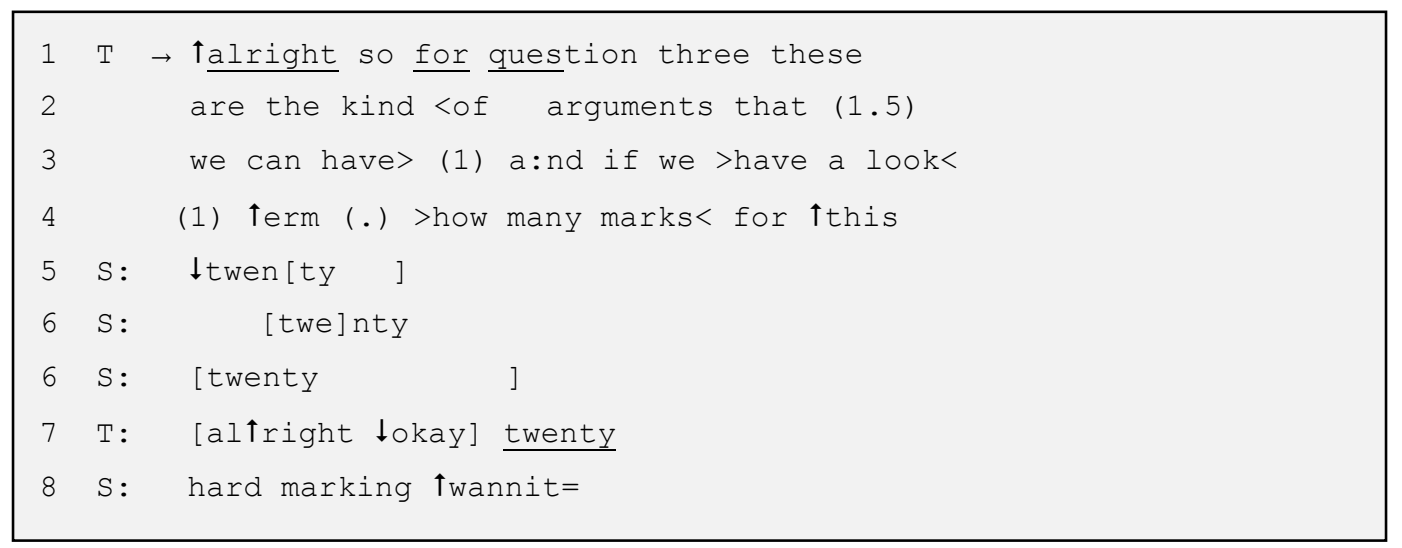

In this extract above, " alright" stands as an initial with high intonation, combined and followed by "so". The teacher's use of " alright" acts or marks the end of his point, and indicates changing to another task. It can be noted that this "alright" is used in a parallel way to "Okay". Indeed, Beach (1993) maintains that "alright" is a functional corresponding of okay in pre-closings. However, the transition marker "so" placed at the middle of the turn performs and acts as giving a summary, which initiates a return to the previous talk (House, 2013). The teacher's "alright" has an impact on the student's collaboration and influences inviting more talk, where it seems from the analysis above that when the teacher uses "alright" he closes the sequence and moves to another activity. "Alright" is both backward and forward looking; it indicates receipting the last turn and indicating a slight change in activity. The "so" therefore seems to mark the beginning of a summary.

\section{The Response Token "mhm" in the Teacher's Third Turn}

Here the "Mm hm" is placed to demonstrate that the teacher is showing affiliation and agreement with the student's response. Therefore, the teacher's turn is incomplete, and the expectation is that the student should continue. For clarity in the data there are continuers written in the transcription as "mhm", "mm"hmm", however, they all function exactly same, except when they are joined with falling or rising intonation, where they have different function in terms of their continuation in turns. 
4.1 “ $\uparrow$ Mhm” at the Initial Positions Standing Alone

Extract 7 [AE:TST: August 2015]

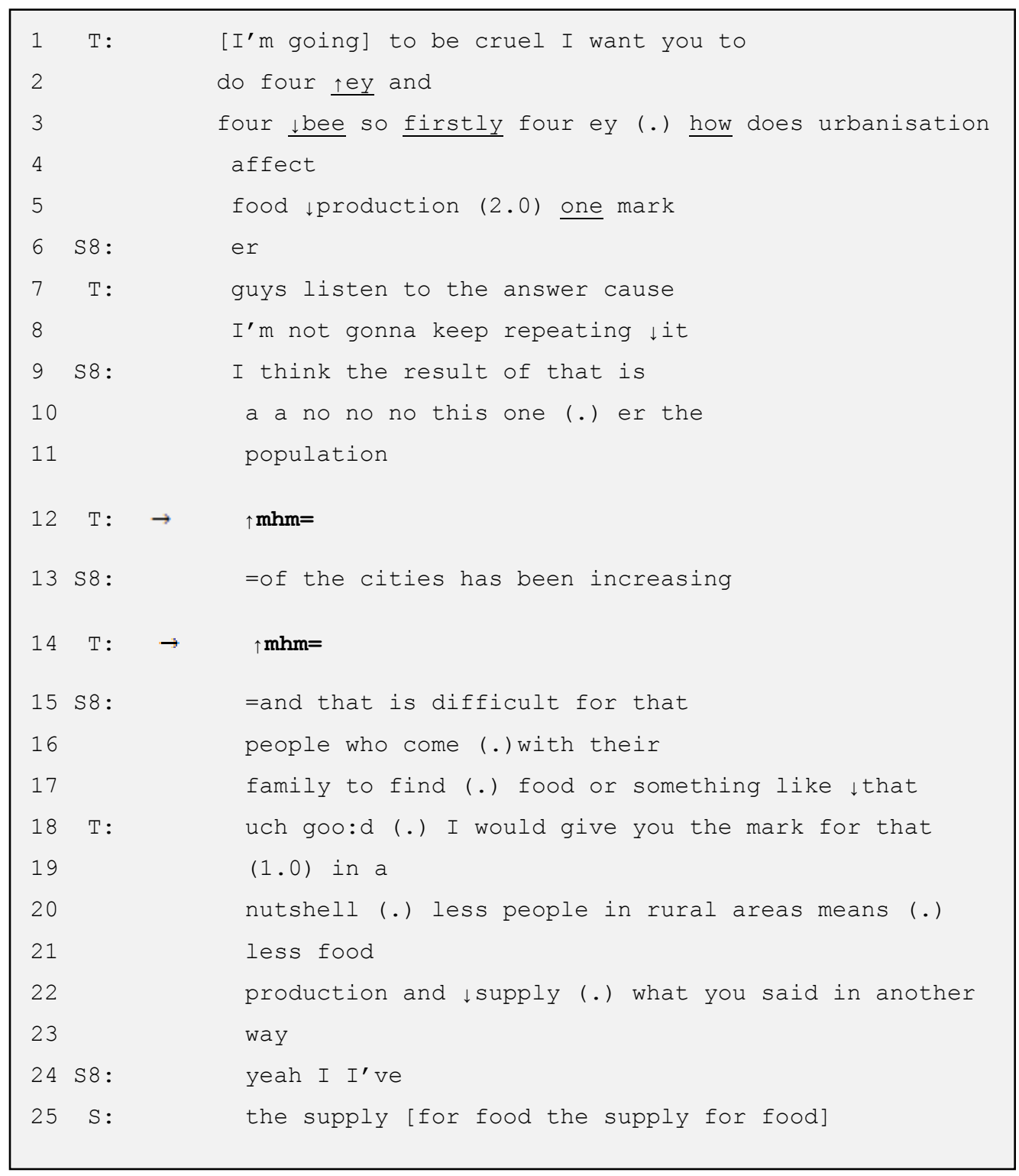

The teacher initiates his question using a Wh-question in line 3-5. A response by S8 in lines 9-11 is followed by the particles or "passive recipiency" (Jefferson 1983, 1993), with rising pitch in the third turn as an assessment. The student keeps holding the floor, as there is talk continuing after reaching the transition place, as can be seen in the latching in the teacher's turn. Again, the teacher uses another continuer token " $\uparrow \mathrm{mhm}=$ " as in line 14 with high intonation showing agreement and affiliation. Moreover, both continuers occur at the third turn performing as an assessment. 


\section{Macrothink}

Extract 8 [AE:TST: July 2015]

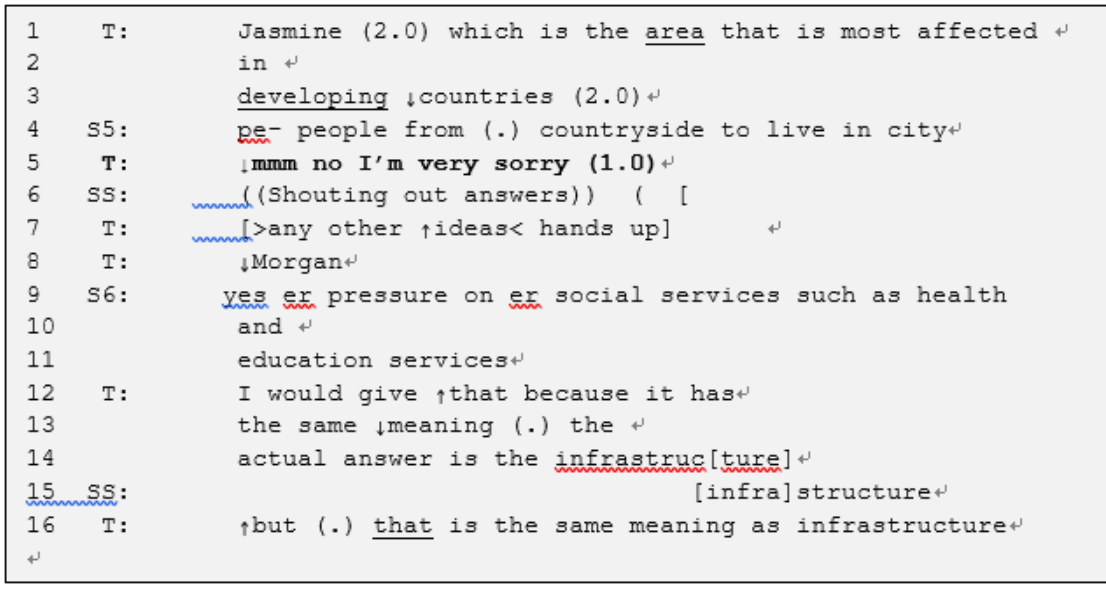

Here, the teacher is selecting who the next speaker is by nominating Jasmine. The first initiation in line 1 asking " $\downarrow$ Jasmine (2.0), which is the area that is most affected in developing $\downarrow$ countries, ” after a (2.0) seconds pause, the student gives a response in line 3, followed by a dispreferred response in the third turn as a disagreement (Pomerantz, 1984). This time, the continuer " $\downarrow \mathrm{mmm}$ " appears with falling intonation and is aligned with a dispreferred response in no "I'm very sorry (1.0)". Here, the continuer " $\downarrow \mathrm{mmm}$ " is combined with no as a dispreferred response (Pomerantz, 1984), and also with the assessment "I' $m$ very sorry (1.0") showing affiliation and marking it as sequence closing, moving to another student by initiating "[> any other $\uparrow$ ideas $<$ ”.In line with Gardner (1997) "Mhm and "hmm" with a rising or falling contour was found to be an expression of heightened involvement, showing affinities with assessment tokens. It can be seen as a weak version of items, such as Wow, Great, or Amazing. This up-down intonation contour is characteristic many assessments" ( p. 147).

\section{The Response Token "Oh" in the Teacher's Third Turn}

One of the characteristics of "Oh" is that it can be combined with other responses, such as an assessment as in the following extract.

Extract 9 [AE: TST: April 2015]

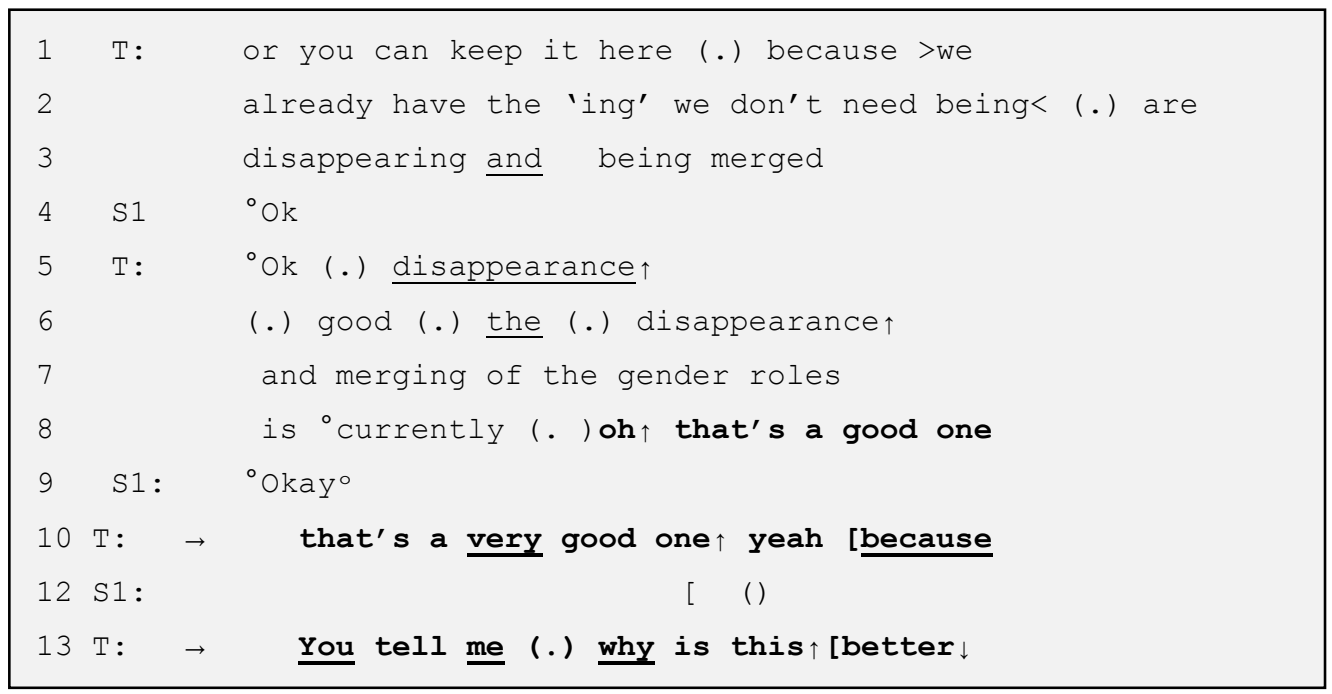




\section{$\Lambda$ Macrothink}

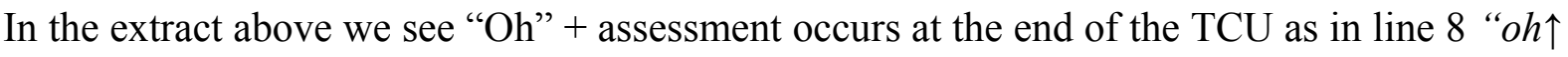
that's a good one". Here, the teacher produces "Oh" with rising intonation, expressing or marking agreement with the student's writing, with a positive assessment (upgrade) good, (Waring, 2008; Wong \& Waring, 2009). Seemingly, the teachers' "Oh" with rising tone marks, as surprised and impressed with the student writing. This could close the sequence. However, she doses another upgraded assessment and ends up continuing, since the teacher has treated the preceding information as a complete action. Accordingly, the student orients to the teacher's response as closing and produces the acknowledgement token "o Okay ${ }^{\circ}$ ". However, in the following turn as in line 10 the teacher continues the sequence and builds on the pervious turn and produces a positive assessment "very good" (see chapter six in positive assessments), indicating there is more to add. Here "Oh" does less as a "change-of-state (Heritage, 1984a). The interactional "Oh" in the teacher's turn is different from that in normal conversation. In everyday conversation, recipients normally supply [oh + assessment] at the end of informing for assessing whether the informing of the news was good or bad (Heritage 1984a). In comparison, what happens prior to the [oh + assessment] in the extract above is not an informing but the teacher here imposes a positive assessment on the student response

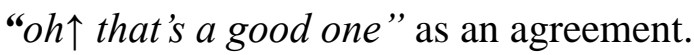

\section{1 "Oh” as a State of Change Along With Other Responses}

Extract 10 [AE:TST: April 2015]

\begin{tabular}{|c|c|}
\hline $\begin{array}{l}66 \\
67\end{array}$ & $\begin{array}{l}\text { OKAY (.) so you seeing if the aims are very } \\
\text { clear and > the rout map is in< there } \downarrow\end{array}$ \\
\hline 68 & $\uparrow$ over all \\
\hline 69 & $(0.3)$ \\
\hline 70 & (.) begi::ns with $s$ or [O] \\
\hline 71 & [it is linking part of the ((inaudible)) \\
\hline 72 & presentation linked or not \\
\hline 73 & $\mathrm{~T}: \quad \rightarrow \uparrow 0:: \mathrm{h}$ whe-whether the $\mathrm{i} \uparrow$ deas are linked whether \\
\hline 74 & they \\
\hline 75 & are using good linking language(.) but even \\
\hline 76 & mo:re than that (. ) think about uhm \\
\hline 77 & (0.2) think about the order another word for \\
\hline 78 & order $(2.0)$ \\
\hline 79 & zaheh : organise \\
\hline 80 & organisation(.) so organisation or the structure \\
\hline 81 & of the presentation a: :llofthose things will be \\
\hline 82 & really useful to comment on okay. \\
\hline
\end{tabular}


In line 73, “O::h" occurs in the turn initial as response to the students' answer. The teacher marks change of state. Here the teacher "Oh" combined with a partial repetition of the student answer for indicating clarity to the whole class. However, the teacher closes the sequences by saying "but even mo:re than that (.) think about uhm", which means it is not the acceptable answer. The teacher is searching for an adequate response when she starts initiating a new TCU after 2.0 seconds of pauses, as in line 77 (0.2) think about the order another word for order (2.0)", considering the previous turn as a sequences closure. One can say that apart from the state of change, the teacher is also producing understanding checks, although she could initiate repair through questions such as 'what do you mean'. However, the teacher proposes a remedy for the trouble by producing an understanding check, in line 73.

\section{Discussion}

The analysis reveals that the teacher's third turn recurrently involves of several elements, which works for different functions. Analysis has shown that these responses may invite contribution or block the continuation to talk from the student or block the continuation of the sequence, thus leading to a shift in tasks.

The response tokens such as "Okay" "alright", "Oh" "mhm" are recurrent features in the teacher's third turn. Such tokens have distinctive functions. In terms of their functional role, some tokens such as "Okay", "alright" and "right" function as evaluations of the students' responses. However, in terms of their sequential positions, some responses close the sequence, while others invite further contribution, for example, "Oh" has a multi-functional role. Apart from acting as a change-of-state token, "Oh" invites further talk, in particular when it is delivered with high intonation, in opposition to the findings of "Oh" in everyday conversation, where "Oh" may receive a confirmation without encouraging elaboration in the subsequent turn (Maynard, 2003).

Response token are very flexible and can be used to close the sequence or invite further talk. Their functions are related to transitions, pauses and intonation. The analysis has shown such response tokens play a fundamental role in constructing and shaping the sequence, in terms of (a) evaluation, (b) managing the sequence. Teachers use these responses to produces evaluation on the students' response and the students orient to the teachers' third turn as an evaluative response. The findings are summarised below:

It was found that responses "Righ" $\mathrm{\uparrow} \uparrow$ and "Mm" $\uparrow$ or $\uparrow$ "Mhm" both invite further talk when they are produced with high intonation. They share the same characteristics but "Right" often to be much stronger in confirming the student 's response than "Mhm or "Mm". The analysis shows that "Okay" has a multifunction use a finding verifies Beach's (1993) claim that "okay" usages are both closure relevant and continuative" (p. 341).

"Okay" and "Right" mark points in the conversation where satisfactory intelligence has been received. Such responses indicate the closing and transition of the topic and can enact a boundary in the conversation. Additionally, they can also be interpreted as the signals of asymmetrical discourse, where one of the participants is a potential role controller. In other words, the teacher is responsible for extending the sequence by providing his/her evaluative 
feedback either through closing or unclosing the sequence. This supports other results obtained of the present research such as O'Keeffe and Adolphs (2008) and Lee (2017).

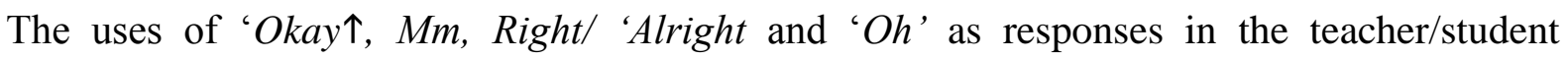
interaction are marked as conversational features where much of the focus is on their influences in the ongoing sequence. The findings show that such responses display important features in the teacher's third turn. They have functions that normally relate to their positions and the way talk is constructed throughout the sequences.

It is apparent from the analysis that response tokens do function differently when they sand alone and when they combined with other responses. In terms, of standing alone they close the sequence and no further talk is required. When they are combined with other response apart of providing evaluation on the student response of the second turn, they also launch a related action in the next turn.

It was found from the analysis that some response tokens such as "Okay", "Alright" and "Right" do function as evaluation on the student responses, while other responses do other thing than just evaluation. Such as inviting student contribution or closing down the sequence and changing tasks.

In general, "Okay" indicates the transition from one utterance of talk to another. "Alright" seemingly functions much in a similar manner to "Okay". This contradicts Turner's views (1999) he, argues that "Okay" and "Alright" have a distinctive usage. According to, Turner's argument, "Alright" has a major mark in shifting topics or moving to another activity, whereas "Okay" marks delicate shifts, with more focus within the unchanged topic (cited in Vickers \& Goble, 2011). Recently, a study conducted by Walsh \& O'Keeffe (2010) reveals that the response token "Okay" is found more profoundly at the beginning of interactions with other cluster responses. In the present study, it was found that tokens such as "Okay" and "Right", "Oh" are found mostly in the teacher third turn. Another finding was such tokens can be combined with other responses. This combination feature works differently. For example, in some cases they close the sequence and no additional talk is added whereas, in another environment they invite students' contributions for further talk.

In terms of their contribution, these responses are valuable in contributing to the organisation of the sequences. They help continue and close the sequences recurrently contributing to shifting to another topic and summarising what has been said. They are responsible for inhibiting student participation in a sense, some inviting contribution and some merely closing the sequence. Also, in terms of their multifunctionality, they are used to organise the progression of the talk and manage the transitions between opening and closing sequences. The results show that such responses demonstrate important features in the teacher's third turn. Response tokens have functions that normally relate to their positions and the way talk is constructed throughout the sequences. This study contributes particularly, to the investigation of the nature of the teacher 'third turn. It examines an extensive range of patterns sequentially and concludes showing more variation and complexity. Previous studies (for instance Margutti \& Drew, 2014; Lee, 2007; Abhakorn, 2017), have only examined one specific aspect of interaction in different settings and have not looked at larger sequences to 
see how the three-part sequences chain together. However, this analysis has demonstrated how the teachers' third turn has a multifaceted role in different sequences. It is not simply feedback or evaluation. The analysis has revealed that this turn performs a range of actions.

\section{Conclusion}

In conclusion, the current study has investigated the multifunctionality of the response tokens in the teacher's third turn. As shown from the analysis not all responses do the same function in the teacher's third turn. Apart from confirming and acknowledging the student responses and maintaining listenership, some invite further contribution, others close and shift to another topic that designates closing the sequence.

\section{References}

Abhakorn. (2017). Pedagogical functions of sequences organization of talk in the EFL classroom. Theory and Practice in Language Studies, 7(1), 29-36. https://doi.org/10.17507/tpls.0701.04

Beach, W. A. (1993). Transitional regularities for "casual' "Okay" usages. Journal of Pragmatics, 19(4), 325-352. https://doi.org/10.1016/0378-2166(93)90092-4

Ebshaina, A. (2019). Investigating Three-part Sequence in Classroom interaction: A Case study of Pre-Sessional Program (PSP) as English for Academic Purposes (EAP) University Classroom. PhD dissertation. University of Huddersfield, Huddersfield.

Gardner, R. (1997). The conversation object mm: A weak and variable acknowledging token. Research on language and Social Interaction, 30(2), 131-156. https://doi.org/10.1207/s15327973rlsi3002_2

Gardner, R. (2005). Acknowledging Strong Ties between Utterances in Talk: Connections through 'Right' as a Response Token. Conference of the Australian Linguistic Society.

Gardner, R. (2007). The Right connections: Acknowledging epistemic progression in talk. Language in Society, 36(3), 319-341. https://doi.org/10.1017/S0047404507070169

Heritage, J. (1984). A Change of State Token and Aspects of its Sequential Placement. In J. M. Atkinson, \& J. Heritage (Eds.), Structures of social action (pp. 299-345). Cambridge: Cambridge University Press. https://doi.org/10.1017/CBO9780511665868.020

Heritage, J., \& Clayman, S. (2010). Talk in action: interactions, identities, and institutions. Chichester: Wiley-Blackwell. https://doi.org/10.1002/9781444318135

House, J. (2013). Developing pragmatic competence in English as a lingua franca: Using discourse markers to express (inter) subjectivity and connectivity. Journal of Pragmatics, 59, 57-67. https://doi.org/10.1016/j.pragma.2013.03.001

Huq, R.-U., \& Amir, A. (2015). When the Tokens Talk: IRF and the Position of Acknowledgement Tokens in Teacher-Student Talk-in-Interaction. Novitas-Royal (Research on Youth and Language), 9(1), 60-76. 


\section{Al Macrothink}

International Journal of Linguistics ISSN 1948-5425 2020, Vol. 12, No. 2

Hutchby, I., \& Wooffitt, R. (1998). Conversation Analysis: Principles, practice and applications. Cambridge, England: Polity.

Hutchby, I., \& Wooffitt, R. (2008). Conversation analysis (2nd ed.). Cambridge: Polity.

Jefferson, G. (1993). Caveat speaker: Preliminary notes on recipient topic-shift implicature. Research on Language and Social Interaction, 26(1), 1-30. https://doi.org/10.1207/s15327973rlsi2601_1

Lee, Y.-A. (2007). Third turn position in teacher talk: Contingency and the work of teaching. Journal of Pragmatics, 39(6), 1204-1230. https://doi.org/10.1016/j.pragma.2006.11.003

Lee. (2017). The Multifunctional Use of a Discourse Marker okay by Korean EFL Teachers. Foreign Language Education Research, 21, 41-65.

Margutti, P., \& Drew, P. (2014). Positive evaluation of student answers in classroom instruction. Language and Education, 28(5), 436-458. https://doi.org/10.1080/09500782.2014.898650

O'Keeffe, A., \& Adolphs, S. (2008). Using a corpus to look at variational pragmatics. Response tokens in British and Irish discourse.

Pomerantz, A. (1984). Agreeing and disagreeing with assessments: Some features of preferred/dispreferred turn shaped. In J. Atkinson, \& H. M. John (Eds.), Structures of social action (pp. 57-101). Cambridge University Press: Cambridge. https://doi.org/10.1017/CBO9780511665868.008

Psathas, G. (1995). Conversation analysis: the study of talk-in-interaction (Vol. 35). Thousand Oaks, Calif; London: Sage. https://doi.org/10.4135/9781412983792

Rymes, B. (2015). Classroom discourse analysis: A tool for critical reflection. Routledge. https://doi.org/10.4324/9781315775630

Schegloff, E. A. (1982). Discourse as an interactional achievement: Some uses of 'uh huh'and other things that come between sentences. Analyzing Discourse: Text and Talk, 71, 93. https://doi.org/10.1017/CBO9780511791208

Schegloff, E. A. (2007). Sequence organization in interaction: A primer in conversation analysis. Cambridge University Press.

Schegloff, E. A., \& Sacks, H. (1973). Opening up closings. Semiotica, 8(4), 289-327. https://doi.org/10.1515/semi.1973.8.4.289

Sert, O. (2015). Social interaction and L2 classroom discourse. Edinburgh University Press.

Sinclair, J. M., \& Coulthard, M. (1975). Towards an analysis of discourse: The English used by teachers and pupils. Oxford: Oxford University Press.

Ten Have, P. (2007). Doing conversation analysis: A practical guide (2nd ed.). London: Sage. https://doi.org/10.4135/9781849208895 


\section{Macrothink}

International Journal of Linguistics

ISSN 1948-5425 2020, Vol. 12, No. 2

Vickers, C., \& Goble, R. (2011). Well, Now, Okey Dokey: English Discourse Markers in Spanish-Language Medical Consultations. Canadian Modern Language Review, 67(4), 536-567. https://doi.org/10.3138/cmlr.67.4.536

Walsh, S. (2011a). Exploring classroom discourse: Language in action. Taylor \& Francis. https://doi.org/10.3138/cmlr.67.4.536

Waring, H. Z. (2008). Using explicit positive assessment in the language classroom: IRF, feedback, and learning opportunities. The Modern Language Journal, 92(4), 577-594. https://doi.org/10.1111/j.1540-4781.2008.00788.x

Wong, J. (2000). Delayed next turn repair initiation in native/non-native speaker English conversation. Applied linguistics, 21(2), 244-267. https://doi.org/10.1093/applin/21.2.244

Wong, J., \& Waring, H. Z. (2009). 'Very good' as a teacher response. ELT Journal, 63(3), 195-203. https://doi.org/10.1093/elt/ccn042

\section{Notes}

Note 1. This article is written from the Doctorate Thesis by 'ASMA. Ebshaina (2019) Investigating Three-part Sequence in Classroom interaction: A Case study of Pre-Sessional Program (PSP) as English for Academic Purposes (EAP)University Classroom.

Note 2. The AE stands for the researcher's initials, TST stands for Teacher Student Talk, followed by the month and the year 2015 .

\section{Copyrights}

Copyright for this article is retained by the author(s), with first publication rights granted to the journal.

This is an open-access article distributed under the terms and conditions of the Creative Commons Attribution license (http://creativecommons.org/licenses/by/4.0/) 